\title{
OPTIMALISASI PEMBELAJARAN BERBASIS-SOSIAL MEDIA: PENGGUNAAN FITUR RELAY PADA APLIKASI LINE SEBAGAI UPAYA PENINGKATAN KREATIVITAS MENULIS DALAM BAHASA INGGRIS
}

\author{
Shania Meiriestiani, Tania Agustinie, Haddad Alwi Dalimunte \\ qory246@gmail.com \\ Mahasiswa Fakultas Keguruan dan Ilmu Pendidikan Universitas Ibn Khaldun
}

\begin{abstract}
ABSTRAK
Bahan ajar yang familiar merupakan sesuatu yang penting karena dapat meningkatkan kreativitas siswa. Pada era seperti ini, bahan ajar yang familiar dapat ditemukan dari lingkungan sekitar siswa. Seperti sosial media yang sangat familiar bagi siswa. Namun tidak semua sosial media memiliki fitur yang sesuai untuk dijadikan bahan ajar. Melalui aplikasi Line yang menyediakan fitur Relay, siswa akan memiliki kesempatan untuk menemukan ideide baru ketika membuat sebuah penulisan karya tulis. Sehingga hasil yang mereka dapatkan menjadi lebih kreatif dan mereka mudah untuk memahami ide-ide yang mereka telah pikirkan sebelumnya.
\end{abstract}

Kata Kunci: Fitur Relay, Kreativitas Menulis, Optimalisasi Pembelajaran.

\section{PENDAHULUAN}

Dalam pembelajaran, hal yang paling mendasar adalah bagaimana informasi dapat dipahami dan diterima. Pembelajaran dilakukan melalui sebuah interaksi antara seorang guru dengan siswanya yang bertujuan agar bahan ajar yang ingin disampaikan oleh seorang guru dapat diterima dengan baik oleh siswa-siswanya. Seorang guru akan menjelaskan bahan ajar yang identiknya didapatkan dalam sebuah buku menggunakan bahasa yang sesuai kepada siswa-siswanya. Proses inilah yang dinamakan proses pembelajaran dan seorang guru akan menggunakan bermacam-macam metode dalam prosesnya. Dewasa ini, seorang guru akan menggunakan metode yang mudah dilakukan namun mudah dipahami oleh siswa-siswanya. Namun seorang guru harus memiliki kemampuan metodologik agar proses pembelajaran dapat dikembangkan dengan baik dan tujuan dapat dicapai, kemampuan ini mengharuskan guru memahami, menguasai dan melaksanakan sejumlah metode mengajar seperti yang dikemukakan oleh Supriadie dan Darmawan (2013) dan juga siswa perlu meningkatkan kreativitas agar potensi-potensi pemahaman yang dimiliki dapat digali lebih dalam.

Kreativitas sulit didapatkan apabila siswa kurang tertarik dengan bahan ajar yang ia miliki. Namun, kreativitas ini sangat dibutuhkan untuk menulis sebuah karya tulis. Kreativitas ini memiliki factor internal dan eksternal, menurut Rosalina dan Julio (2016) factor internal ini berasal dari diri sendiri, seperti pembawaan, 
ekspresi diri, dan kebiasaannya. Faktor eksternal ini berasal dari luar dirinya, seperti lingkungan keluarga dan sekolah. Maka dari itu, faktor eksternal ini sangat mempengaruhi peningkatan kreativitas siswa dalam proses pembelajaran.

Selain itu, bahan ajar juga digunakan untuk mendukung tujuan pembelajaran. Penerapan bahan ajar dari sesuatu yang familiar dapat menjadi salah satu aspek yang meningkatkan kemampuan kreativitas siswa. Berbeda apabila dalam penggunaan bahan ajar yang tidak familiar bagi mereka, mereka akan kesulitan mendapatkan ketertarikan terhadap pembelajaran. Karena pada era ini, sesuatu yang tidak familiar bagi mereka adalah sesuatu yang kurang dipaami dan akan mereka abaikan. Siswa akan mencari sesuatu yang familiar untuk mereka pahami. Maka bahan ajar yang familiar ini dapat didapatkan dari halhal di sekitar kita seperti pemanfaatan media sosial, buku berbasis elektronik, dan aplikasi-aplikasi pembantu pembelajaran. Dalam hal ini, seorang guru dan siswa dituntut untuk memahami penerapan bahan ajar yang familiar di sekitarnya agar tujuan dari pembelajaran tersampaikan dengan baik karena menurut Sanjaya (2005, p. 31) "dalam suatu proses pembelajaran guru tanpa siswa tidak akan memiliki makna”.

Sosial media merupakan salah satu bahan ajar yang familiar bagi siswa di sekolah saat ini. Media sosial ini sangat dekat kaitannya dengan kehidupan siswa, karena sosial media mendominasi siswa untuk terus melihat perkembangan kehidupan dunia luarnya. Selain itu, penggunaan sosial media cenderung lebih dititikberatkan pada penulisan pesan informasi dengan maksud untuk menyampaikan apa yang ada dalam pikirannya. Secara tidak langsung kemampuan berpikir dalam menulis pesan informasi di dominasi kreativitas.

Sosial media yang umumnya digunakan untuk menulis dalam bentuk pesan informasi adalah sosial media yang menyediakan fitur tulis pesan. Tujuan adanya fitur tulis pesan ini adalah memudahkan pengguna sosial media menyampaikan satu pesan dalam pikirannya kepada orang banyak. Beberapa sosial media memiliki peraturan untuk mengirim pesan kepada publik. Fitur dalam sosial media ini dapat membantu bahan ajar dalam suatu pembelajaran. Salah satunya aplikasi yang menyediakan fitur ini adalah aplikasi Line. Selain itu, aplikasi Line menyediakan fitur tulis pesan dalam bentuk Relay. Pesan yang disampaikan melalui Relay dapat berupa gambar atau text card.

Relay dalam bahasa Indonesia memiliki arti menyampaikan. Sesuai dengan namanya Relay ini dapat digunakan sebagai media tulis pesan untuk menyampaikan bahan ajar. Dalam penggunaannya, Relay ini bisa digunakan oleh seorang guru untuk menyampaikan konten yang dikemas dalam bentuk gambar atau text card. Melalui Relay diharapkan siswa dapat meningkatkan kreativitasnya karena fitur ini menampilkan media bahan ajar pada aplikasi Line yang umumnya sudah familiar untuk mereka.

Bahan ajar yang dapat disampaikan melalui fitur ini adalah bahan ajar mengenai konten topik dalam penulisan, khususnya dalam bahasa Inggris. Karena melalui Relay dalam bentuk gambar atau text card konten topik akan lebih mudah tersampaikan maksud dan tujuannya. Bentuk gambar sebagai penyampaian konten bisa disesuaikan dengan topiktopiknya agar siswa dapat merefleksikan visualnya lebih luas lagi sehingga potensi 
kreativitasnya meningkat. Selain itu, bentuk text card memiliki background dengan warna-warna dasar tujuannya karena setiap warna memiliki kesan dan pesan bagi yang melihatnya sehingga.

Saat ini, siswa cenderung lebih menyukai media familiar karena menurut mereka melalui media tersebut mereka sedang dipacu untuk menunjukkan ketertarikannya dan juga sedang dipacu untuk memunculkan ide-ide kreatif. Sehingga dalam menulis bahasa Inggris kreativitas siswa bisa digunakan dan hasilnya tulisannya menjadi lebih menarik, selain itu siswa mampu membangun hubungan antara hal-hal yang baru bagi mereka (Johnson, 2002).

Maka dengan adanya Relay pada aplikasi Line ini, diharapkan mampu meningkatkan kreativitas siswa. Karena ketika siswa melihat secara langsung

\section{GAGASAN}

\section{Kondisi Terkini}

Kondisi terkini yang terjadi adalah kurangnya kreativitas menulis siswa karena tidak adanya kemauan menulis. Siswa menganggap menulis adalah kegiatan yang sulit dilakukan karena siswa diharuskan menguasai isi dan maksud dalam pembuatan karya tulis.

Selain itu, siswa kurang tertarik dengan penggunaan media yang dianggap tidak membuat kreativitas mereka menjadi terpacu. Mereka tidak mendapatkan hal-hal baru yang memunculkan imajinasi mereka. Sehingga kreativitas siswa sama sekali tidak digunakan dalam menulis dan kreativitas mereka pun tidak mengalami peningkatan. konten topik pada Relay-nya, mereka akan melibatkan dan menerapkan imajinasi serta potensi pemahaman yang luas pada hasil karya tulisnya.

\section{Tujuan}

Gagasan ini bertujuan untuk meningkatkan kreativitas siswa sekolah dalam memahami konteks yang akan siswa pilih untuk menjadi topik pembahasannya dalam menulis menggunakan bahasa Inggris melalui penggunaan relay pada aplikasi Line.

\section{Manfaat}

Gagasan ini memiliki manfaat bagi guru untuk memberikan alternatif media bahan ajar yang familiar agar kreativitas siswa-siswa dapat terasah dan meningkat dalam menulis bahasa Inggris sehingga tujuan dari pembelajaran dapat tercapai.

\section{Solusi yang Pernah di Ajukan Sebelumnya}

Berbagai solusi untuk meningkatkan kreativitas siswa dalam menulis bahasa Inggris telah banyak dilakukan. Salah satunya dengan menggunakan facebook di sebagai aplikasi untuk menulis. Dalam proses menulis menggunakan facebook, siswa diharuskan menunjukan kemampuan menulisnya untuk essay. Cahyono (2015) mengatakan bahwa dalam penggunaan facebook ini dapat meningkatkan kemampuan menulis essai dalam bahasa Inggris. Beliau menggunakan processbased approach dalam pengajarannya. Siswa menunjukkan kemampuan yang terbaiknya dalam penulisan essai melalui facebook.

$\begin{array}{rrrr}\text { Namun, } & \text { proses } & \text { menulis } \\ \text { menggunakan } & \text { facebook } & \text { ini } r \text { tidak } \\ \text { menunjukkan } & \text { kreativitas } & \text { siswanya. }\end{array}$


Facebook ini hanya menonjolkan sisi kemampuan siswa dalam menulis dengan topik yang telah ditentukan dibandingkan menyoroti kreativitas menulis dan isi apa yang ingin disampaikan.

Penggunaan facebook ini tidak efektif karena tujuan pembelajaran yang diinginkan untuk meningkatkan kreatifitas siswa dalam menulis tidak tercapai. Yang sebenarnya dibutuhkan adalah meningkatkan kreativitas menulis siswa dalam bahasa Inggris tanpa meninggalkan tujuan dan maksud dari pembelajaran.

\section{Gagasan yang di Ajukan}

Gagasan mengenai penggunaan fitur Relay pada aplikasi Line dalam membantu meningkatkan kreativitas menulis siswa dalam bahasa Inggris ini berangkat dari kurangnya ketertarikan siswa dalam menulis. Dengan demikian siswa diberi kesempatan dalam menggunakan imajinasinya ketika mencari hal-hal baru dari apa yang telah mereka lihat pada Relay-nya. Kemudian pada saat mereka mulai menulis karya tulisanya, siswa akan memiliki lebih luas lagi ide-ide yang mereka pikirkan. Sehingga ide-ide yang muncul ini akan membuat sifat kreatif mengalami peningkatan.

\section{Pihak-Pihak}

$$
\text { yang }
$$

Membantu

\section{Mengimplementasikan Gagasan}

1. Sekolah, menyediakan akses internet gratis agar pembelajaran berbasis sosial media ini efektif dilakukan.

2. Orangtua siswa, mengizinkan anaknya dalam penggunaan sosial media di handphone dengan tujuan positif untuk media pembelajaran.

3. Guru, memberikan kesempatan penggunaan handphone dalam kegiatan belajar mengajar di kelas.

\section{Langkah-langkah yang dapat di Capai}

1. Sekolah dapat menerapkan bahan ajar familiar ini di setiap kelas dan juga menguatkan keyakinan guru-guru di sekolah akan tercapainya tujuan pengajaran meskipun menggunakan media yang tidak familiar bagi guruguru namun familiar bagi siswa-siswa di sekolah. Sekolah tetap memantau jalannya pembelajaran untuk mengetahui dampak dari penggunaan bahan ajar familiar ini. Selain itu, sekolah harus menindaklanjuti dampak negatif yang timbul dari bahan ajar familiar ini agar dampak negatif yang ada bisa di evaluasi. Sekolah juga harus menyediakan fasilitas yang mendukung dalam pengaksesan internet sehingga penggunaan sosial media atau bahan ajar familiar ini berjalan sesuai. Berikut ini adalah cara-cara yang harus dilakukan dalam penggunaan fitur Relay pada aplikasi Line.

a. Tahap Awal

- Pengunduhan aplikasi Line di Play Store atau App Store.

- Login apabila telah memiliki akun Line dengan memasukkan nomor telepon, lalu tunggu pengiriman nomor verifikasi pada nomor telepon yang telah dimasukkan.

- Sign Up apabila belum pernah memiliki akun Line, dengan mengisi form yang disediakan oleh aplikasi Line. 
b. Tahap Pembuatan Relay

- Fitur Relay ini berada pada menu bar Timeline bergambar jam dinding mengarah kepada pukul 20.00 .

- Pada pojok bawah sebelah kanan terdapat gambar pena, apabila di klik memiliki 3 bagian,fitur salah satunya adalah fitur Relay.

- Pilih fitur Relay untuk menyampaikan konten topik untuk bahan ajar menulis dalam bahasa Inggris.

- Pada Relay akan disediakan kolom judul, berikan judul Topik Penulisan.

- Lalu pilih gambar untuk mengunggah gambar yang akan menjadi konten topik.
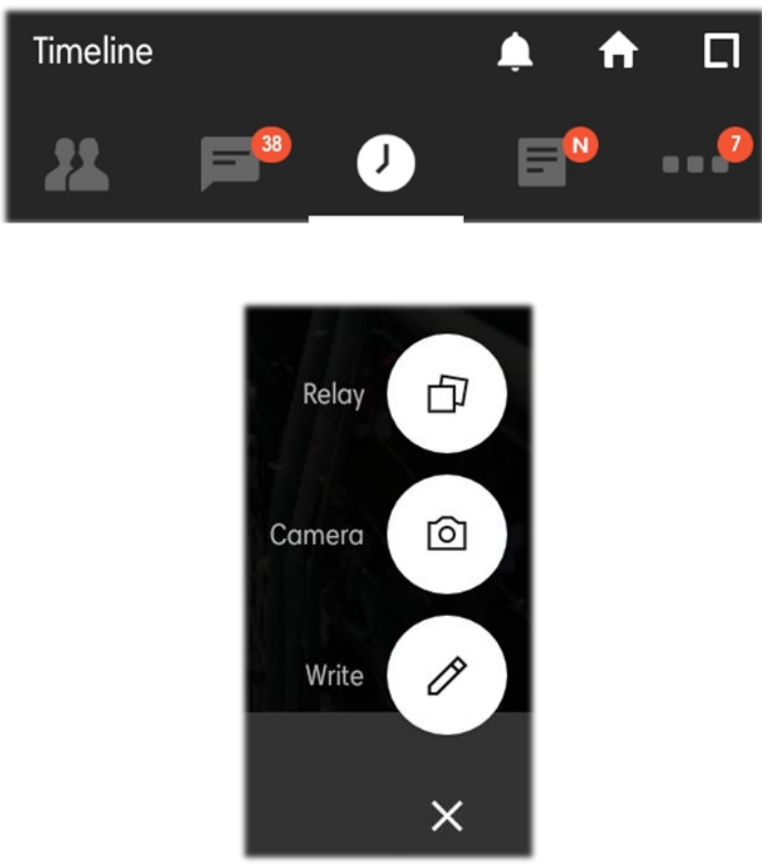

2
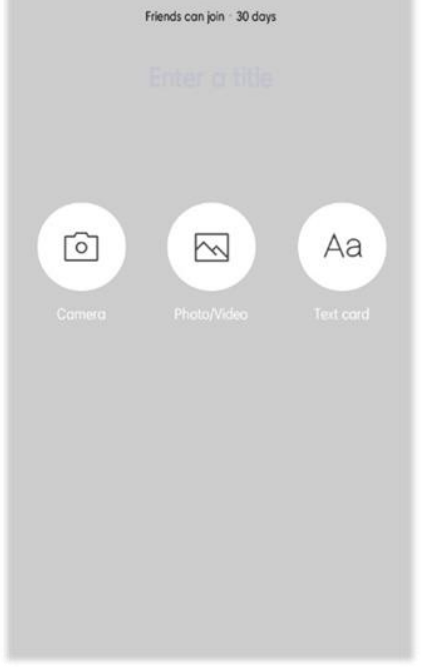

2

Friends can join 30 days

Enter a title 
- Pilih gambar yang sesuai dan cantumkan keterangan mengenai gambar tersebut.

- Klik add dan Relay yang dibuat akan muncul di Timeline pada aplikasi Line.

Relay yang telah dibuat ini akan menjadi konten topik pada proses menulis dalam bahasa Inggris. Siswa akan lebih mudah mengeksplorasi isi dalam karya tulisnya karena mereka dipermudah dari melihat gambar di Relay-nya. Tak luput dari itu, kreativitas dalam menulis pun

\section{KESIMPULAN}

\section{Gagasan yang di Ajukan}

Dari yang telah di jelaskan pada paparan diatas, dapat disimpulkan bahwa penggunaan sosial media dalam pembelajaran ini dapat diterapkan untuk meningkatkan kreativitas siswa dalam menulis bahasa Inggris dan

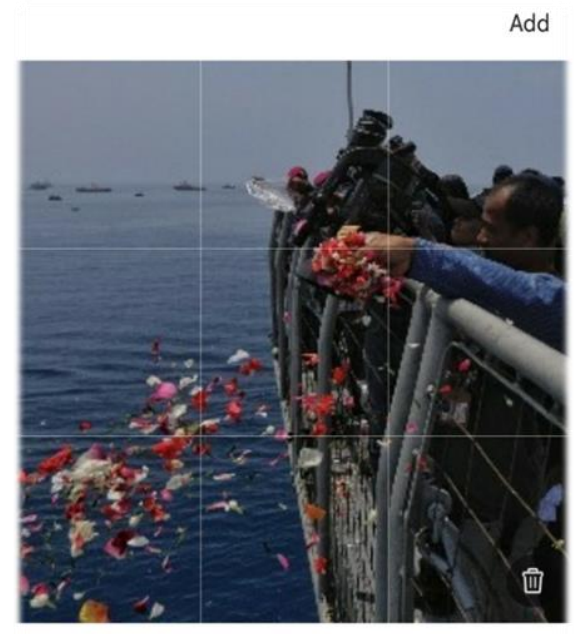

Keluarga korban penumpang Lion Air JT610 menaburkan bunga di Laut Jawa kawasan utara Karawang, Jawa Barat.
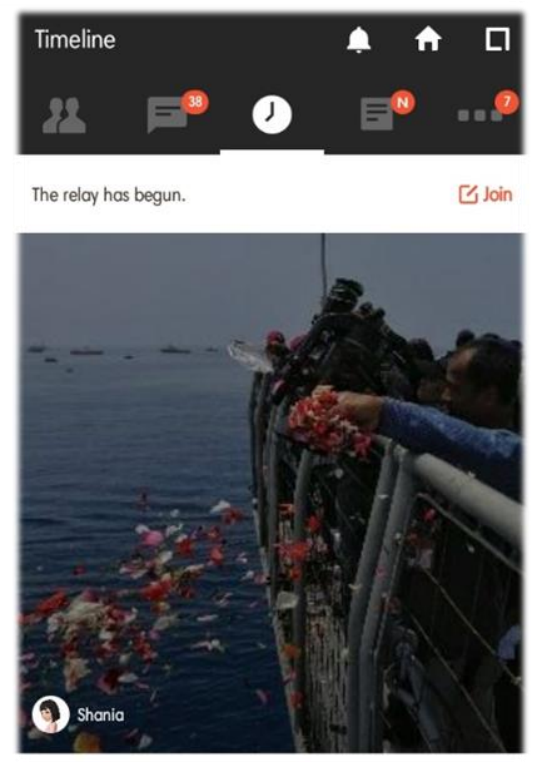

akan ditunjukkan melalui cara mereka memikirkan hal-hal yang berbeda dan menjadi lebih luas. Pada akhirnya, karya tulis yang mereka hasilkan akan sangat berbeda jika dibandingkan melalui media bahan ajar yang biasa digunakan.

mengoptimalkan penggunaan sosial media, sehingga sosial media ini dapat berperan dalam peningkatan kemampuan siswa di sekolah pada era ini. Gagasan ini juga memberikan kesempatan kepada sekolah, guru, dan siswa untuk memanfaatkan 
sesuatu yang familiar menjadi bahan ajar yang bermanfaat.

Teknik Implementasi yang akan di Lakukan

Teknik mengimplementasikan gagasan ini adalah dengan membangun hubungan antara guru dan siswa di sekolah melalui sosialisasi pengoptimalan bahan ajar familiar berupa sosial media.

\section{DAFTAR PUSTAKA}

Agnes Rosalina dan Owen Julio. 2016. Pengaruh Kreativitas Siswa terhadap Kemampuan Menulis Karya Sastra

Johnson, Elaine

B. 2002. Contextual Teaching and Learning. Corwin Press, Inc., Thousand Oaks: California.

Wina Sanjaya. 2008. Perencanaan dan Desain Sistem Pembelajaran. Prenada Media Group: Jakarta.

\section{Prediksi Hasil yang akan di Capai}

Hasil yang akan di capai adalah bentuk kemampuan siswa dalam menulis bahasa Inggris yang mengalami peningkatan karena mereka menggunakan kreativitasnya. Hasil karya tulis yang dibuat oleh mereka akan memiliki perbedaan karena ide-ide yang digunakan memiliki perluasan setelah fitur Relay ini digunakan.

Didi Supriadie dan Deni Darmawan. 2013. Komunikasi Pembelajaran. PT Remaja Rosdakarya: Bandung.

Bambang Yudi Cahyono. 2015. Using Facebook to Enhance English Department Students' Skill in Writing English Essay. 